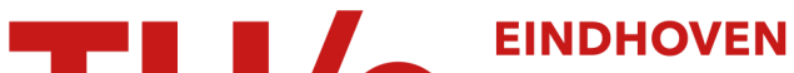 \\ UNIVERSITY OF \\ TECHNOLOGY
}

\section{Equation of state of polymer solutions}

\section{Citation for published version (APA):}

Simha, R., Nies, E. L. F., \& Stroeks, A. A. M. (1991). Equation of state of polymer solutions. Polymer Preprints, 32(1), 489-490.

\section{Document status and date:}

Published: 01/01/1991

\section{Document Version:}

Publisher's PDF, also known as Version of Record (includes final page, issue and volume numbers)

\section{Please check the document version of this publication:}

- A submitted manuscript is the version of the article upon submission and before peer-review. There can be important differences between the submitted version and the official published version of record. People interested in the research are advised to contact the author for the final version of the publication, or visit the $\mathrm{DOI}$ to the publisher's website.

- The final author version and the galley proof are versions of the publication after peer review.

- The final published version features the final layout of the paper including the volume, issue and page numbers.

Link to publication

\section{General rights}

Copyright and moral rights for the publications made accessible in the public portal are retained by the authors and/or other copyright owners and it is a condition of accessing publications that users recognise and abide by the legal requirements associated with these rights.

- Users may download and print one copy of any publication from the public portal for the purpose of private study or research.

- You may not further distribute the material or use it for any profit-making activity or commercial gain

- You may freely distribute the URL identifying the publication in the public portal.

If the publication is distributed under the terms of Article 25fa of the Dutch Copyright Act, indicated by the "Taverne" license above, please follow below link for the End User Agreement:

www.tue.nl/taverne

Take down policy

If you believe that this document breaches copyright please contact us at:

openaccess@tue.nl

providing details and we will investigate your claim. 
EQUATION OF STATE OF POLYMER SOLUTIONS

\section{R. Simha}

Department of Macromolecular Science, Case Western Reserve University Cleveland, Ohio 44106, U.S.A.

E. Nies and A. Stroeks Department of Polymer Technology EIndhoven University of Technology $5600 \mathrm{MB}$ Eindhoven, The Netherlands

\section{Introduction}

The starting point is a statistical thermodynamics of a chainmolecular, configurationally disordered dense system (1). The theory was subsequently shown to be pertinent also for organic solvent - type fluids (2). A generalization to compatible mixtures followed (3). Finally a refinement, particularly significant in the treatment of phase equilibria and pressure effects, was developed (4).

In what follows we review briefly the essentials of the theory for single and multi-constituent systems under single phase conditions. We continue with applications to the three types of concern here, i.e. polymer melts, organic solvents, and their mixtures.

\section{Theory: Single Constituent}

Each unit (segment or molecule) executes thermal motions in the field of its neighbours. For the computation of this field a mean field approximation is employed which places these neighbours onto average positions defined by the sites of a lattice. In order to enhance configurational disorder, a fraction $h$ of vacant sites is introduced. It may be viewed as an excess free volume function over that prevailing in the fully occupied lattice. The temperature and volume or pressure dependence of this characteristic structure function is uniquely determined by the minimization of the configurational free energy which may formally be written as:

$$
F[V, T, h(V, T)]
$$

Thus $h$ is eliminated from eq. 1 by the condition

$$
(\partial \mathrm{F} / \partial \mathrm{h})_{\nabla, \mathrm{T}}=0
$$

The free volume function enters into the partition function and hence $F$ through three factors, viz.

a) A combinatory factor arising from the mixing of empty and occupied sites.

b) A free volume term characteristic of cell theories. It is computed here by approximating the cell potential by a square well.

c) A lattice energy contribution, again characteristic of cell theories.

From the explicit form of eqs. 1 and 2, with the specifications a)-c) there follows the equation of state

$$
\mathbf{P}=-(\partial \mathrm{F} / \partial \mathrm{V})_{\mathrm{T}}
$$

Before presenting the explicit results, we note that the evaluation of item a) above had originally proceeded through Flory's treatment (1). Recently, a modification was introduced which utilizes an approach by Huggins (4). Whereas in the former version the site fraction $y-1-h$ is the pertinent quantity, in the latter the ratio

$$
q=(1-\alpha) y /(1-\alpha y)
$$

with $\alpha=\gamma(1-1 / s), \gamma-2 / z$, and $s$ the number of segments per molecule, is the important quantity. Here q represents the fraction of intersegmental contacts of the $s$-mer.
Going with the lattice coordination number $z$ to infinity and $\alpha$ to zero, reduces Huggins' to Flory's expression. Introducing the further abbreviations $A=1.011, B=$ 1.2045, $Q=y V$, and indicating by tildes reduced variables, we obtain the two coupled equations

$$
\begin{aligned}
\tilde{\mathrm{PV}} / \tilde{\mathrm{T}}= & 1(1-\eta)+2(1-\alpha) \mathrm{y}\left(\mathrm{AQ}^{-4}-\mathrm{BQ}^{-2}\right) /(1-\alpha \mathrm{y}) \tilde{\mathrm{T}} \\
0= & (3 \eta-1+\alpha \mathrm{y}) /((1-\eta)(1-\alpha \mathrm{y}))+ \\
& (1-\alpha) \mathrm{y}\left[2 \mathrm{BQ}^{-2}-3 \mathrm{AQ}^{-4}+4 \alpha \mathrm{y}\left(\mathrm{AQ}^{-4}-\mathrm{BQ}^{-2}\right)\right] / \\
& 2 \tilde{\mathrm{T}}(1-\alpha \mathrm{y})^{2}-(1 \mathrm{l}(1-\mathrm{y}) / \mathrm{y}+1-1 / \mathrm{s}- \\
& \ln (1-\alpha \mathrm{y}) / \gamma \mathrm{y}-\alpha / \gamma) \mathrm{c}_{\mathrm{s}}
\end{aligned}
$$

where $\eta=2^{-1 / 6} \mathrm{y}(1-\alpha) /\left[(1-\alpha y) Q^{1 / 3}\right)$. Putting $\alpha=0$ reduces eqs. $1 a$ and $2 a$ to the earlier expressions (1).

The characteristic scaling parameters of pressure, volume and temperature are combinations of the intersegmental attraction energy $\epsilon *$ and segmental repulsion volume $v *$ for a segment of mass $M_{s}$. To these is added a parameter $c_{s}-c / s$, where $3 c$ is to represent the number of external or volume dependent modes in the s-mer. The importance of this parameter was first recognized by Prigogine, Trappeniers and Mathot (5). It is to be taken as a measure of the perturbation of internal rotations of the chain in addition to motions of the chain as a whole, in the dense medium. We note that the parameter $c_{s}$ influences the magnitude of the free volume ratio $h$. In actual applications one either makes an a priori numerical assig nment which amounts to replacing the ensemble of real nmers by an ensemble of $s$-mers with identical physical properties, or takes $c$ as the parameter for the $n$-mer to be extracted from experimental data. The connection between theory and experiment is then made by appropriate shifts of the reduced onto the experimental PVT surface. This determines the scaling parameters, defined by the following relations:

$\mathrm{P} *=\mathrm{z}(1-\alpha) \epsilon * / \nu^{*} ; \mathrm{V} * \mathrm{~s} v^{*} ; \mathrm{T}^{*}=\mathrm{z}(1-\alpha) \epsilon^{*} /\left(\mathrm{c}_{\mathrm{s}} \mathrm{R}\right)$

Equation 5 retains its validity for both versions of the theory discussed. Its quantitative success, combined with extensive PVT measurements by Simha and by Zoller and their colleagues, has yielded detailed parameter values. We observe that the two versions of the theory $(\alpha \geq 0)$ in eqs. $1 a$ and $2 a$, are equally successful, but result in numerically different scaling parameters (4).

\section{Theory: Hixtures}

The generalization to multi-component systems has been given (3) by adopting a simplification introduced by Prigogine et al. in their theory of mixtures, based on the simple cell model (5). That is, the repulsion volume $v *$ is replaced by an average, instead of dealing explicitly with the problem of packing differently sized spheres. This the problem of packing differently sized spheres. This sized segments (not necessarily equal sized chemical repeat units). When moreover the random approximation is adopted, the result is a single fluid theory. That is, the scaled eqs. $1 \mathrm{a}$ and $2 \mathrm{a}$ retain their formal validity with all parameters now explicit functions of composition and of self and cross interactions $(3,6)$. For a binary system of components $a$ and $b$ we have the following relation for the mean interaction parameters:

$$
\begin{aligned}
& \left\langle\epsilon *>\langle u *\rangle^{m}=\epsilon *_{a a} v *_{a a}^{m} q_{a}^{2}+2 \epsilon *_{a b} v *_{a b}^{m} q_{a} q_{b}+\right. \\
& \epsilon *_{b b} v *_{b b}{ }^{m} q_{b}^{2} ; m=2,4
\end{aligned}
$$

The $q_{i}$ represent the contact fractions

$q_{i}=x_{i}\left[s_{i}(z-2)+2\right] / \Sigma x_{i}\left[s_{1}(z-2)+2\right] ; \quad i=1,2$ with $x_{i}$ mole fractions. Moreover, averages $\langle c\rangle=\Sigma x_{i} c_{i} ;\langle s\rangle=\Sigma x_{i} s_{i}$ enter. The scaling parameters, eqs, 5 and 4 , are then redefined in terms of these compositional averages. From their definitions there follows the relation 
$\mathrm{P} * \mathrm{~V} * / \mathrm{T} *=\mathrm{c}_{\mathrm{s}} \mathrm{R}$

with the analogous expression for the mixture. Thus, once the complete equations of state for the constituents and the experimental volume-temperature function of the mixture at atmospheric pressure $(\tilde{P} \rightarrow 0)$ are known, the scaling pressure $\langle P *\rangle$ and hence the complete equation of state for the mixture are also known.

As noted previously, random mixing was assumed between molecules and vacancies, as well as between molecules of different species. An evaluation of the effect of non-randomess is under consideration (7).

\section{Experimental: Polymer, Solvent and Solution}

As mentioned earlier, extensive experimentation on and analysis of polymer melts has taken place. Whereas Simha and colleagues were concerned with vinyl-type compounds, zoller and colleagues included in their studies also various engineering plastics, compatible polymer also various engineering plastics, compation a very satisfactory agreement between experiment and theory. An illustration is seen in Figure 1 for two single polymers, polystyrene and poly (o-methylstyrene), investigated over pressures up to 2 kbar ( 8 . We observe the relation between measurement and prediction, and the superposition of the two data sets. That is, a principle of corresponding states obtains. That this should be so for sufficiently high obtains. That this should be so for sufficienty halue of $c_{s}$ is apparent from eq. 2a. The results displayed in Figure 1 are typical for the many polymer systems investigated.

The predictions of the theory have been examined also for low molecular mass compounds. Normal paraffins, for example, offer an opportunity to proceed to much higher pressures for the present purpose than in polymer melts. Again satisfactory comparisons have ensued for both homogeneous fluids and their mixtures. References are given in Ref. (3). For the subsequent discussion of phase equilibria (see the following paper) however, organic solvents are of primary interest. Benzene, carbon vents are of primary interest. $2,3,10)$, as well as mixtures of the latter two (3). Figure 2 shows a series of isobars for benzene and cyclohexane respectively.

Similar results have been obtained for polymer solutions (10). Of special interest in connection with its phase behavior, to be discussed in the following paper, is the pair polystyrene-cyclohexane. Specific volumes at several compositions, molar masses and temperatures have been determined (11). The procedure used in the comparison between experiment and theory serves to illustrate the capabilities of the latter in accounting for both equation of state properties and phase relations. That is, the of state properties and phase relations. The the mixtures were derived from phase data to be discussed in the folwere derived. The results are shown in Fig. 3. The maximum deviation between prediction and measurement is below $1 \%$ which is gratifying indeed. However, we should also note at this point that the reverse procedure i.e. the prediction of phase relations from equation of state data, is not satisfactory for a quantitative analysis of the subtle compositional and pressure effects to be considered in what follows.

\section{Conclusions}

The equilibrium theory outlined yields quantitative1y successful equations of state for dense disordered assemblies of low and high molar mass constituents, and their mixtures. It opens the way for a consideration of the non-equilibrium glass. Of particular interest in the the non-equilext are the equation of state contributions to present context are the equation of state contributions to This is the central topic of the following presentation.

\section{References}

1. Simha, R., Somcynsky, T., Macromolecules, 1969, 2, 341.

2. Jain, R.k., Simha, R., J. Chem. Phys., 1980, 72, 4909.

3. Jain, R.K., Simha, R:, Macromolecules, 1980, 13, 1501. Nies. E., Stroeks, A., Macromolecules, 1990, 23, 4088 .

5. Prigogine, I., Trappeniers, N., Mathot, V., Discus sions Faraday Soc., 1953, 15, 93.

6. Stroeks, A., Nies, E., Macromolecules, 1990, 23, 4092 .

7. Nies, E., Xie, H., Unpublished.

8. Quach, A., Simha, R., J. Appl. Phys., 1971, 42, 4592 .

9. Jain, R.K., Simha, R., J. Chem. Phys., 1979, 70, 2792 . 263,905 .

11. Wolf, B.A., private communication.

\section{List of Figures}

Fig. 1. Scaled isotherms for melts of polystyrene and

Fig. 2. Isobars of benzene and cyclohexane: Lines,

Fig. 3 . theory.

Volume of polystyrene-cyclohexane mixtures as function of composition at different temperatures. Points, experimental; Lines, theory.

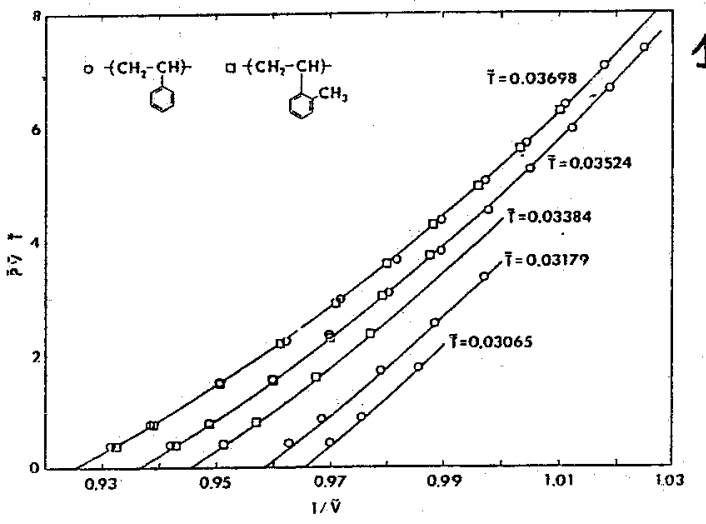

2.
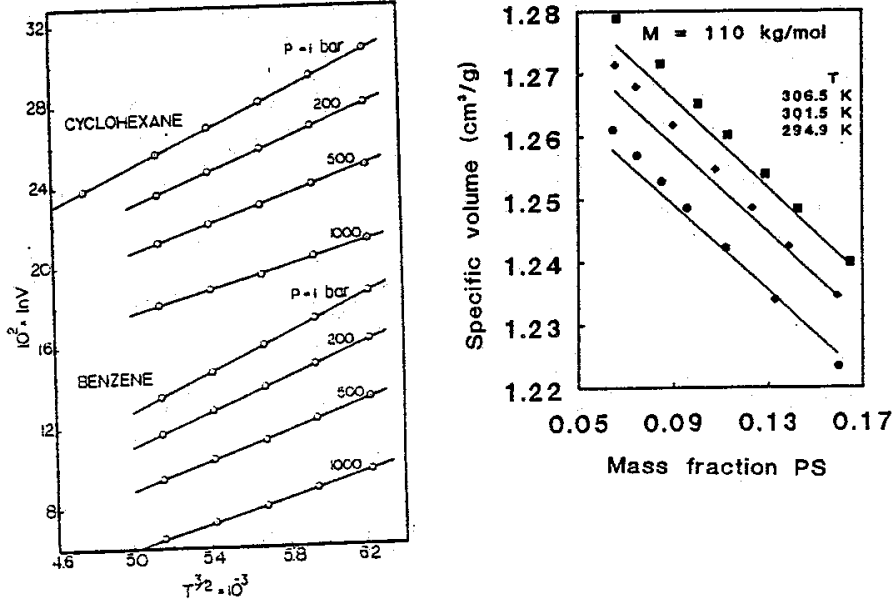